\title{
Susceptibility Vessel Sign on MRI Predicts Favorable Clinical Outcome in Patients with Anterior Circulation Acute Stroke Treated with Mechanical Thrombectomy
}

\author{
R. Bourcier, S. Volpi, B. Guyomarch, B. Daumas-Duport, (D)A. Lintia-Gaultier, C. Papagiannaki, J.M. Serfaty, and (DH. Desal
}

\begin{abstract}
BACKGROUND AND PURPOSE: The susceptibility vessel sign on MR imaging has been reported to indicate acute occlusion from erythrocyte-rich thrombus. The purpose of this study was to evaluate the influence of the susceptibility vessel sign seen on MR imaging before treatment on the clinical outcome after mechanical thrombectomy for anterior circulation acute stroke.
\end{abstract}

MATERIALS AND METHODS: We retrospectively included 73 consecutive patients who were treated for anterior circulation acute stroke by mechanical thrombectomy from December 2009 to September 2013. Each patient underwent MR imaging before mechanical thrombectomy. The presence (susceptibility vessel sign+) or absence of the susceptibility vessel sign (susceptibility vessel sign-) was recorded. Mechanical thrombectomy was performed either alone or in association with IV tPA according to the site and time after occlusion. Good functional outcome was defined by an mRS $\leq 2$ at 3 months in susceptibility vessel sign + and susceptibility vessel sign - groups. Patient clinical characteristics, initial NIHSS score and ASPECTS, site of occlusion, time between onset to groin puncture, TICl after mechanical thrombectomy, NIHSS score at day 1, and spontaneous hyperattenuation on CT at day 1 were also analyzed.

RESULTS: Fifty-three patients with susceptibility vessel sign + and 20 with susceptibility vessel sign - were included in our study. mRS $\leq 2$ at 3 months occurred in $65 \%$ patients in the susceptibility vessel sign + group and $26 \%$ in the susceptibility vessel sign - group $(P=.004)$. On multivariate analysis, the susceptibility vessel sign was the only parameter before treatment that could predict mRS $\leq 2$ at 3 months (OR, 8.7; 95\% Cl, 1.1-69.4; $P=.04$ ).

CONCLUSIONS: Our study strongly suggests that the susceptibility vessel sign on MR imaging before treatment is predictive of favorable clinical outcome for patients presenting with anterior circulation acute stroke and treated with mechanical thrombectomy.

ABBREVIATIONS: ACAS $=$ anterior circulation acute stroke; $\mathrm{GRE}=$ gradient recalled-echo; $\mathrm{MT}=$ mechanical thrombectomy; SVS $=$ susceptibility vessel sign

S troke is a leading cause of adult disability. Approximately twothirds of stroke survivors have long-term functional deficits that affect their quality of life. ${ }^{1,2}$ Very recently, large prospective randomized trials have proved the clinical benefit of endovascular recanalization and, in particular, mechanical thrombectomy (MT) in patients with proximal anterior circulation acute stroke

\section{Received January 22, 2015; accepted after revision April 18}

From the Departments of Diagnostic and Interventional Neuroradiology (R.B., S.V., B.D.-D., A.L.-G., H.D.) and Diagnostic Cardiac and Vascular Imaging (J.M.S.), Centre Hospitalier Universitaire Nantes Hôpital G et R Laënnec, Nantes, France; Centre d'investigation clinique Thorax (B.G.), l'institut du thorax, Centre Hospitalier Universitaire Nantes, Nantes, France; Institut National de la Santé et de la Recherche Médicale, UMR1087 (B.G., J.M.S., H.D.), l'institut du thorax, Nantes, France; Centre national de la recherche scientifique (B.G,), UMR 6291, Nantes, France; and Department of Diagnostic and Interventional Neuroradiology (C.P.), Centre Hospitalier

Régional Universitaire de Tours, Bretonneau Hospital, Tours, France.

J.M.S. and H.D. have participated equally in the supervision of this study.

Please address correspondence to Romain Bourcier, MD, CHU NANTES HGRL, Department of Diagnostic and Interventional Neuroradiology, Nantes, F-44000

France; e-mail: romain.bourcier2@gmail.com

http://dx.doi.org/10.3174/ajnr.A4483
(ACAS) ${ }^{3,4}$ In these studies, patients were included on the basis of the presence of a proximal artery occlusion without any characterization of thrombus subtypes (ie, fibrin-rich or erythrocyte-rich thrombus). A gradient recalled-echo (GRE) MR imaging sequence is commonly used to identify brain hemorrhage, and it may also differentiate fibrin-rich from erythrocyte-rich thrombus on the basis of the presence of a susceptibility vessel sign (SVS). ${ }^{5,6}$

There has been no study addressing the prognostic value of SVS in predicting good clinical recovery after MT, to our knowledge. The goal of our study was, therefore, to investigate whether the presence of the SVS is related to better clinical outcomes after MT with stent retrievers in patients presenting with ACAS.

\section{MATERIALS AND METHODS}

This was a retrospective descriptive study according to the protocol of stroke treatment at our center. Observational retrospective studies according to the French legislation (articles L.1121-1 


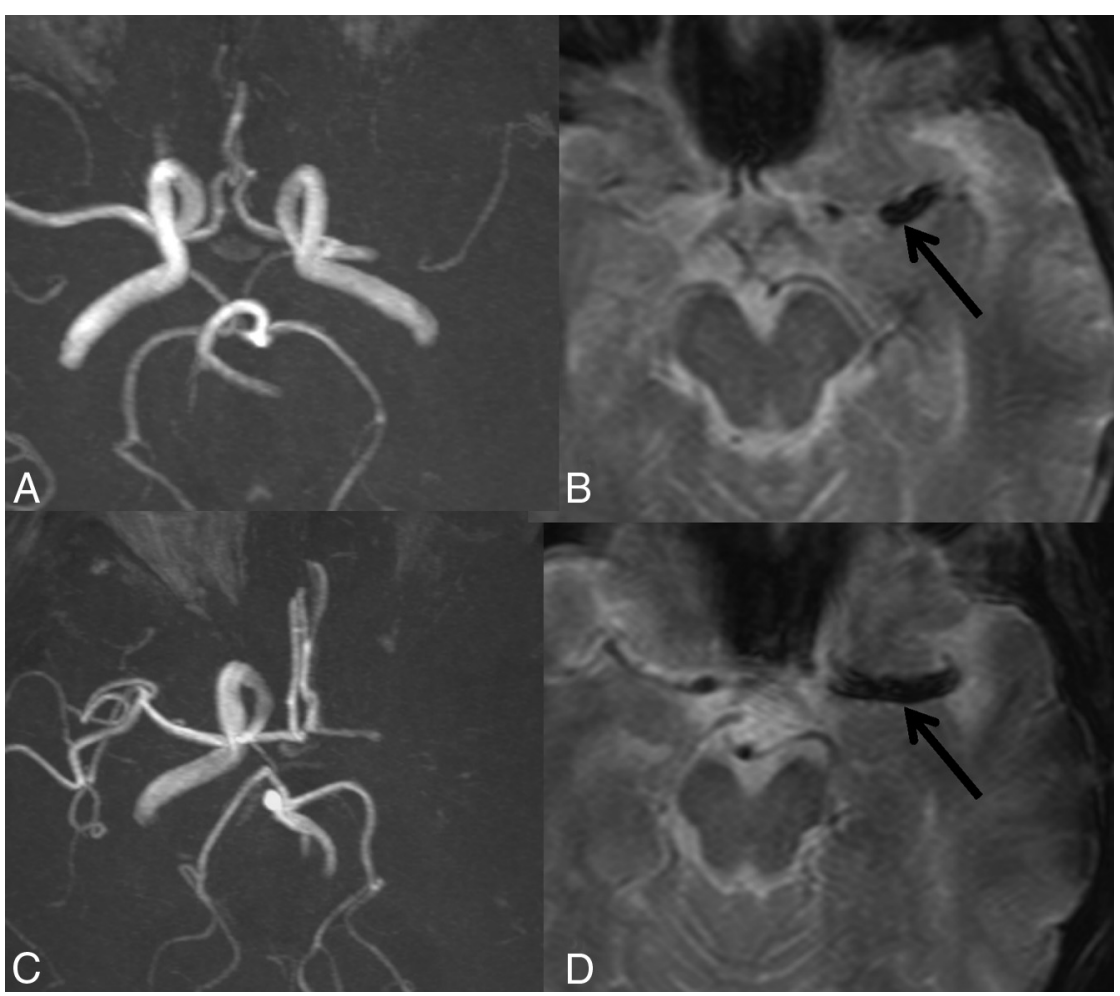

FIG 1. MR imaging showing MCA and ICA-MCA occlusions with SVS (black arrow). A and B, TOF and $\mathrm{T}^{*}$ sequences show occlusion of the left MCA. $C$ and $D$, TOF and T2* sequences show occlusion of the left ICA-MCA.

paragraph 1 and R1121-2, Public Health Code) do not require an ethics committee approval to use data for an epidemiologic study.

\section{Patients}

We retrospectively included 73 consecutive patients who were treated by MT between September 2009 and December 2013 for ACAS in our center.

All these patients underwent MR imaging before treatment with a GRE T2* sequence and were classified in 2 groups: "SVS +" if they presented an SVS in the occluded artery or "SVS-" if they did not.

Vascular risk factors were registered for each patient and defined as follows: 1) hypertension, when there was a history of antihypertensive medication use, a systolic blood pressure of $\geq 140 \mathrm{~mm} \mathrm{Hg}$, or a diastolic blood pressure of $\geq 90 \mathrm{~mm} \mathrm{Hg}$ at hospital discharge; 2) diabetes mellitus, when the use of hypoglycemic drugs or a random glucose level $\geq 200 \mathrm{mg} / \mathrm{dL}$ or glycosylated hemoglobin level of $>6.4 \%$ on admission were observed; 3 ) hyperlipidemia, when a history of the use of antihyperlipidemic agents was mentioned or a serum cholesterol level of $>220 \mathrm{mg} / \mathrm{dL}$ was present; 4) smoking, whatever the level of consumption; and 5) obesity defined as a body mass index of $>30$.

Initial NIHSS score, site of occlusion, IV tPA before MT, and time between onset and groin puncture were also recorded. Patients with ASPECTS $<5$ on DWI, estimated by the method of Barber et al, ${ }^{7}$ were excluded.

\section{MR Imaging Protocol}

MR imaging was performed on a $1.5 \mathrm{~T}$ magnet (Sonata; Siemens, Erlangen, Germany) with a phased array head coil. First, a GRE
T2* imaging was performed to screen for intracranial hemorrhage and SVS. Acquisition parameters for GRE T2* were the following: TR, $800 \mathrm{~ms}$; TE, 30 ms; section thickness, $5 \mathrm{~mm}$; intersection gap, $1 \mathrm{~mm}$; FOV, $250 \times 250 \mathrm{~mm}$; flip angle, $20^{\circ}$. Second, DWI sequences $b=0, b=500$, and $b=1000$ were acquired, as was an apparent diffusion coefficient map to identify the necrotic core. Acquisition parameters for DWI sequences were set as follows: TR, 6900 ms; TE, $89 \mathrm{~ms}$; section thickness, $5 \mathrm{~mm}$; intersection gap, $0 \mathrm{~mm}$; FOV, $230 \times 230$ $\mathrm{mm}$. Then, a FLAIR sequence was performed with the following acquisition parameters: TR, $9000 \mathrm{~ms}$; TE, $95 \mathrm{~ms}$; section thickness, $5 \mathrm{~mm}$; intersection gap, $0 \mathrm{~mm}$; FOV, $240 \times 210 \mathrm{~mm}$; flip angle, $150^{\circ}$. Finally, a TOF sequence focused on the circle of Willis was obtained to screen large-vessel occlusion. Acquisition parameters for the TOF sequence were the following: TR, $24 \mathrm{~ms}$; TE, $7 \mathrm{~ms}$; section thickness, $0.7 \mathrm{~mm}$; intersection gap, $-3.5 \mathrm{~mm}$; FOV, $180 \times$ $180 \mathrm{~mm}$; flip angle, $20^{\circ}$.

Occlusion of the MCA (either M1 and/or M2) was classified as MCA occlusion. Occlusion involving the ICA ending, extending or not to M1, was classified as ICA occlusion. "SVS" was defined as a hypointense signal on $\mathrm{T}^{*}$ within a vessel, exceeding the size of the homologous contralateral artery diameter (Fig 1). 5,6

All MR imaging and CT on day 1 were analyzed by a junior radiologist (S.V.) and an experienced neuroradiologist (R.B.), and in case of discrepancy, a third experienced neuroradiologist (J.M.S.) analyzed images in consensus.

\section{Endovascular Treatment}

When an MCA or ICA occlusion was observed, MT was performed with or without preliminary IV tPA according to the Rescue, Combined, and Stand-Alone Thrombectomy study and neurologic expertise. ${ }^{8}$

All endovascular procedures were performed on a biplane system (Integris Allura 20/20; Philips Healthcare, Best, the Netherlands) by experienced interventional neuroradiologists (H.D., A.L.-G., B.D.-D.).

An 8F Envoy (Codman \& Shurtleff, Raynham, Massachusetts) guiding catheter was introduced through a femoral sheath into the concerned carotid artery. Navigation into the target vessel was made with a 0.014-inch microguidewire (Traxcess; MicroVention, Tustin, California) and a 0.021-inch microcatheter (Rebar; Covidien, Irvine, California). The microguidewire was exchanged with the MT device. Once the device was deployed, angiography was performed to evaluate its correct placement and expansion. The device was left in place for 2-7 minutes. Then, the fully deployed device together with the delivery microcatheter was 
gently pulled back as a single unit and recovered. Before and during this retrieval, manual aspiration was performed with a $50-\mathrm{mL}$ syringe through the hemostatic valve of the guiding catheter.

Results were assessed according to the TICI grading scale: $0-2 \mathrm{a}$ for failure of recanalization on angiography and $2 \mathrm{~b}-3$ for successful recanalization. ${ }^{9}$ The procedure was repeated 5 times maximum until a TICI score of $2 \mathrm{~b}$ or 3 was obtained. After the fifth attempt, if a TICI score of $2 \mathrm{~b}$ or 3 was not achieved, MT was considered a failure.

\section{Immediate Post-MT Imaging and Follow-Up}

The TICI scores at the end of the procedure were reviewed by a neuroradiologist who did not perform the MT (R.B.).

NIHSS score at day $1, \mathrm{mRS}$, and death at 3 months were retrospectively recorded from patient files. NIHSS and mRS scores ( $\mathrm{mRS} \leq 2$ was considered a good outcome, and $>2$, a bad outcome) after MT were assessed by independent vascular neurologists working in our institution. The presence of spontaneous hyperattenuation on CT on day 1 after MT was also recorded. In the early follow-up period, any other CT control was performed only in case of clinical worsening.

Symptomatic intracranial hemorrhage was defined according to the European Cooperative Acute Stroke Study definition. ${ }^{10}$

\section{Statistical Analysis}

Results were expressed as mean, SD, median, minimum, and maximum for quantitative variables and as count and percentage for categoric variables. Usual bivariate parametric $\left(\chi^{2}\right.$ test or Fisher exact test) statistical tests were used for group comparisons. Logistic regression analysis was used to assess the association of the SVS and the favorable functional outcome 90 days after MT. We used the following clinical characteristics: age, sex, initial and day 1 NIHSS score, ASPECTS, dissection, site of occlusion, SVS, IV tPA, onset-to-groin puncture time, TICI, and spontaneous hyperattenuation on CT on day 1. First, a univariate analysis was performed, and only factors with a $P$ value $\leq .25$ were selected for the multivariate analysis. All statistical tests were 2-sided, and the significance level was set at .05. Statistical analysis was performed by using SAS, Version 9.4 (SAS Institute, Cary, North Carolina).

\section{RESULTS}

\section{Baseline Characteristics}

Among 73 patients (36 men and 37 women; median age, 59 years; range, 25-85 years) treated for ACAS with MT, 53 patients $(73 \%)$ were SVS + and 20 patients $(27 \%)$ were SVS-. Intra- and interobserver agreement $(\kappa)$ for the SVS on MR imaging was 0.86 and 0.86 , respectively. The baseline characteristics are summarized in Table 1 . The median NIHSS score (2-27) at admission was 18.

Occlusion involved the MCA in $47 \%$ of the cases, and the ICA (extending or not to the MCA), in $53 \%$ of cases with 11 ICA cervical dissections included in this group. Ten patients with cervical dissection presented with an SVS+. One was SVS - , but this difference was not statistically significant $(P=$ .27). MT alone was used in $45 \%$ of cases, and IV tPA + MT, in $55 \%$ of cases. Age, cardiovascular risk factors, initial NIHSS
Table 1: Patient characteristics and MRI findings before MT and complications and clinical outcome after MT in patients with and without SVS

\begin{tabular}{|c|c|c|c|}
\hline & $\begin{array}{c}\text { SVS- } \\
(n=20)\end{array}$ & $\begin{array}{c}\text { SVS+ } \\
(n=53)\end{array}$ & $\begin{array}{c}P \\
\text { Value }\end{array}$ \\
\hline \multicolumn{4}{|l|}{ Before thrombectomy } \\
\hline Age (yr) (mean) & $59 \pm 12$ & $59 \pm 14$ & .93 \\
\hline \multicolumn{4}{|l|}{ Sex ratio } \\
\hline Female & $10(50 \%)$ & $27(51 \%)$ & .94 \\
\hline Male & $10(50 \%)$ & $26(49 \%)$ & \\
\hline \multicolumn{4}{|l|}{ Cardiovascular risk factors } \\
\hline Hypertension & $9(45 \%)$ & $18(35 \%)$ & .42 \\
\hline Diabetes & $2(10 \%)$ & $4(8 \%)$ & .67 \\
\hline Hyperlipidemia & $8(40 \%)$ & $14(27 \%)$ & .28 \\
\hline Smoking & $7(35 \%)$ & $9(17 \%)$ & .12 \\
\hline Obesity & $1(5 \%)$ & 7 (13\%) & .43 \\
\hline Initial NIHSS & & & .66 \\
\hline$\leq 10$ & $1(5 \%)$ & $6(11 \%)$ & \\
\hline $10-20$ & $11(55 \%)$ & $27(51 \%)$ & \\
\hline$>20$ & $8(40 \%)$ & $20(38 \%)$ & \\
\hline ASPECTS & & & .68 \\
\hline$\leq 7$ & $8(40 \%)$ & $24(45 \%)$ & \\
\hline$>7$ & $12(60 \%)$ & $29(55 \%)$ & \\
\hline Side of occlusion & & & .45 \\
\hline Left & $14(70 \%)$ & $32(60 \%)$ & \\
\hline Right & $6(30 \%)$ & $21(40 \%)$ & \\
\hline Site of occlusion & & & .37 \\
\hline ICA & $9(45 \%)$ & $30(57 \%)$ & \\
\hline MCA & $11(55 \%)$ & $23(43 \%)$ & \\
\hline Dissection & $1(5 \%)$ & 10 (19\%) & .27 \\
\hline IV tPA & $11(55 \%)$ & $29(55 \%)$ & .98 \\
\hline \multicolumn{4}{|l|}{ Onset-to-groin puncture } \\
\hline$\leq 270 \mathrm{~min}$ & $5(25 \%)$ & $13(25 \%)$ & .98 \\
\hline $270 \mathrm{~min}$ to $360 \mathrm{~min}$ & $8(40 \%)$ & $20(38 \%)$ & \\
\hline$>360 \mathrm{~min}$ & $7(35 \%)$ & $20(38 \%)$ & \\
\hline \multicolumn{4}{|l|}{ After thrombectomy } \\
\hline $\mathrm{TICl} \geq 2 \mathrm{~b}-3$ & $14(70 \%)$ & $43(81 \%)$ & .34 \\
\hline $\begin{array}{l}\text { Lack of spontaneous } \\
\quad \text { hyperattenuation on } \mathrm{CT}\end{array}$ & $11(55 \%)$ & $31(58 \%)$ & .79 \\
\hline NIHSS at day 1 & & & .03 \\
\hline$\leq 10$ & $6(30 \%)$ & $29(55 \%)$ & \\
\hline $10-20$ & $9(45 \%)$ & $21(40 \%)$ & \\
\hline$>20$ & $5(25 \%)$ & $3(6 \%)$ & \\
\hline $\mathrm{mRS} \leq 2$ & $5(26 \%)$ & $33(65 \%)$ & .004 \\
\hline
\end{tabular}

score, ASPECTS, and side of occlusion were similar between the 2 groups (Table 1 ).

\section{Mechanical Thrombectomy}

Mean time from the stroke onset to groin puncture was 255 minutes in patients with SVS and 228 minutes in patients without SVS $(P=.98)$. Successful recanalization (TICI $2 \mathrm{~b}-3)$ was observed in $78 \%$ of patients, in $81 \%$ in the SVS + group and in $70 \%$ in the SVS - group $(P=.34)$ (Table 1$)$.

\section{Short-Term Complications and Mortality after MT}

A spontaneous hyperattenuation on CT at day 1 after MT was observed in 30 (42\%) patients.

Because we performed another CT in the early follow-up only when a clinical worsening occurred, we were not able to distinguish intracranial hemorrhage from contrast extravasation. From these patients, 5 (7\%) developed a symptomatic intracranial hemorrhage, 3 of them belonging in the SVS + group.

The overall short-term mortality was $4 \%$ (3 of 73 patients). 


\begin{tabular}{|c|c|c|c|}
\hline & $\begin{array}{l}\mathrm{mRS} \leq 2 \\
(n=38)\end{array}$ & $\begin{array}{l}\mathrm{mRS}>2 \\
(n=32)\end{array}$ & $\begin{array}{c}P \\
\text { Value }\end{array}$ \\
\hline \multicolumn{4}{|l|}{ Before thrombectomy } \\
\hline Age (mean) & $58 \pm 13$ & $61 \pm 13$ & .25 \\
\hline \multicolumn{4}{|l|}{ Sex ratio } \\
\hline Female & $21(55 \%)$ & $15(47 \%)$ & .43 \\
\hline Male & $17(45 \%)$ & $17(53 \%)$ & \\
\hline \multicolumn{4}{|l|}{ Cardiovascular risk factors } \\
\hline Hypertension & $12(32 \%)$ & $15(48 \%)$ & .16 \\
\hline Diabetes & $2(5 \%)$ & $4(13 \%)$ & .40 \\
\hline Hyperlipidemia & $13(34 \%)$ & $8(26 \%)$ & .45 \\
\hline Smoking & $6(16 \%)$ & $8(26 \%)$ & .37 \\
\hline Obesity & $4(11 \%)$ & $3(10 \%)$ & .61 \\
\hline \multicolumn{4}{|l|}{ Initial NIHSS } \\
\hline$\leq 10$ & $7(18 \%)$ & $0(0 \%)$ & .01 \\
\hline $10-20$ & $21(55 \%)$ & $16(50 \%)$ & \\
\hline$>20$ & $10(26 \%)$ & $16(50 \%)$ & \\
\hline ASPECTS & & & .54 \\
\hline$\leq 7$ & $16(42 \%)$ & $14(44 \%)$ & \\
\hline$>7$ & $22(58 \%)$ & $18(56 \%)$ & \\
\hline \multicolumn{4}{|l|}{ Side of occlusion } \\
\hline Left & 24 (63\%) & $19(59 \%)$ & .75 \\
\hline Right & $14(37 \%)$ & $13(41 \%)$ & \\
\hline Site of occlusion & & & .24 \\
\hline ICA & $17(45 \%)$ & $19(59 \%)$ & \\
\hline MCA & $21(55 \%)$ & $13(41 \%)$ & \\
\hline Dissection & $5(13 \%)$ & $5(16 \%)$ & .52 \\
\hline SVS+ & $33(87 \%)$ & $18(56 \%)$ & .004 \\
\hline IV tPA & $22(58 \%)$ & $17(53 \%)$ & .81 \\
\hline Onset-to-groin puncture & & & .59 \\
\hline$\leq 270 \mathrm{~min}$ & $10(26 \%)$ & $7(22 \%)$ & \\
\hline $270 \mathrm{~min}$ to $360 \mathrm{~min}$ & $16(42 \%)$ & $11(34 \%)$ & \\
\hline$>360 \min$ & $12(32 \%)$ & $14(44 \%)$ & \\
\hline \multicolumn{4}{|l|}{ After thrombectomy } \\
\hline $\mathrm{TICl} \geq 2 \mathrm{~b}-3$ & $34(89 \%)$ & $20(63 \%)$ & .01 \\
\hline $\begin{array}{l}\text { Lack of spontaneous } \\
\text { hyperattenuation on CT }\end{array}$ & $27(71 \%)$ & $13(41 \%)$ & .03 \\
\hline NIHSS at day 1 & & & $<.001$ \\
\hline$\leq 10$ & 31 (82\%) & $3(9 \%)$ & \\
\hline $10-20$ & $7(18 \%)$ & $22(69 \%)$ & \\
\hline$>20$ & $0(0 \%)$ & $7(22 \%)$ & \\
\hline
\end{tabular}

The first patient, a man 85 years of age, had an initial NIHSS score of 24 and SVS - . MT failed with a TICI score of 0 . NIHSS score at day 1 was 24 ; the patient died at day 4 . The second patient, an 83-year-old woman with an initial NIHSS score of 10 , presented with a SVS + and a dissection. Recanalization failed (TICI $=0$ ), and an early intracranial hemorrhage occurred with an NIHSS score at day 1 of 24. Death occurred at day 6 . The third patient was a 75-year-old woman, with an initial NIHSS score of 11 , SVS - . She had a TICI 2 a, and an NIHSS score at day 1 of 20. Death occurred at day 10 .

\section{Clinical Outcome after MT}

Three patients were lost for follow-up. For the remaining patients $(n=70)$, the median NIHSS score $(2-27)$ at day 1 was 12 . The functional clinical outcome 3 months after MT was favorable ( $\mathrm{mRS} 0-2)$ in 38 patients $(54 \%)$ and poor (mRS $3-6)$ in $32(46 \%)$ (Table 2). The NIHSS score at day 1 was lower in the SVS+ group than in the SVS - group $(P=.03)$, and the mRS at 3 months was

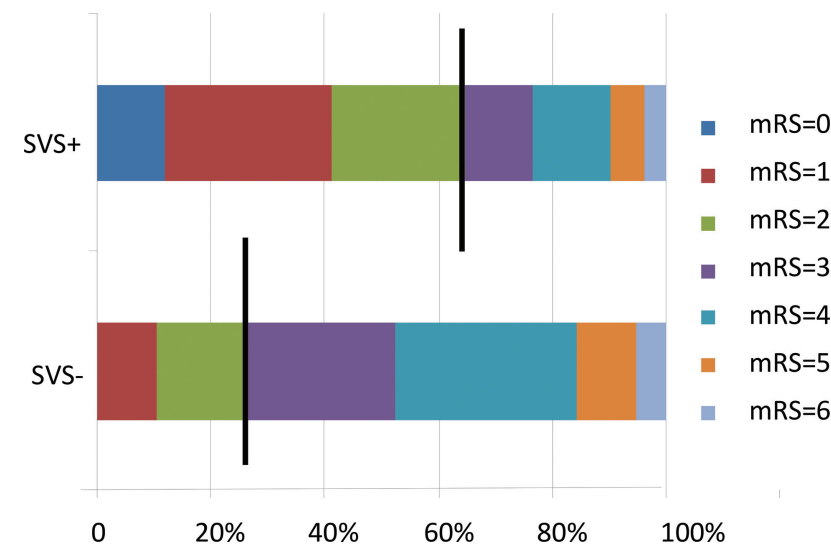

FIG 2. Three-month mRS after MT in patients with SVS $(n=53)$ and in patients without SVS $(n=20)$. Brackets indicate the percentage of patients achieving a good mRS score of $0-2$; mRS scores of $3,4-5$, and 6 represent intermediate neurologic outcome, poor neurologic outcome, and death, respectively.

$\leq 2$ in 5 cases $(26 \%)$ in the SVS - group and in 33 cases $(65 \%)$ in the SVS $+\operatorname{group}(P=.004)$ (Table 1 and Fig 2).

\section{Predictive Factors of Clinical Outcome at 3 Months}

Before MT, only the initial NIHSS score $(P=.01)$ and the presence of SVS $+(P=.004)$ were significantly associated with a good functional outcome (Table 2). On univariate and multivariate logistic regression analysis, good functional outcome was associated only with the presence of a SVS+ (univariate: OR, 5; 95\% CI, 1.6-16.6; $P=.01$; multivariate: OR, 8.7; 95\% CI, 1.1-69.4; $P=.04$ ) (Table 3).

After MT, a TICI $\geq 2 \mathrm{~b}-3(P=.01)$, the lack of spontaneous hyperattenuation on CT $(P=.03)$, and a lower NIHSS score at day $1(\leq 10)(P<.001)$ were significantly associated with a good functional outcome (Table 2). On univariate analysis, a TICI 22b-3 (OR, 5.1; 95\% CI, 1.4-17.9; $P=.01$ ), the lack of spontaneous hyperattenuation on CT (OR, 3.6; 95\% CI, 1.3-9.7; $P=$ .01 ), and a lower NIHSS score at day 1 (OR, 51.5; 95\% CI, $11.8-$ 225.1, $P<.001)$ were significantly associated with a good functional outcome. On multivariate analysis, a lower NIHSS score at day $1(\leq 10)(\mathrm{OR}, 51.9 ; 95 \% \mathrm{CI}, 8.4-320.5 ; P<.001)$ was significantly associated with a good functional outcome (Table 3 and Figs 3 and 4$)$.

\section{DISCUSSION}

Our study shows that in patients with ACAS selected for MT by using stent retrievers, SVS is a strong predictor of favorable clinical outcome before treatment. There is no other study focusing on the ability of SVS to predict mRS, to our knowledge

The GRE T2* MR imaging sequence is widely used in clinical routine to rule out brain hemorrhage and detect arterial thrombus. ${ }^{11}$ Identification of SVS on these GRE T2* sequences is considered reliable and reproducible because studies have shown excellent inter- and intraobserver agreement. ${ }^{12}$ Similarly, our study, excellent intra- and interreader variabilities were observed confirming these results.

Overall, we found that among 73 patients treated for ACAS with MT, SVS was present in 53 patients (73\%). This rate of SVS on GRE T2* imaging was in accordance with previous re- 
Table 3: Univariate and multivariate logistic regression analyses for factors associated with $\mathrm{mRS} \leq 2$

\begin{tabular}{|c|c|c|c|c|c|c|}
\hline & \multicolumn{3}{|c|}{ Univariate } & \multicolumn{3}{|c|}{ Multivariate } \\
\hline & OR & $95 \% \mathrm{Cl}$ & $P$ Value & OR & $95 \% \mathrm{Cl}$ & $P$ Value \\
\hline Age & 0.9 & $0.9-1.01$ & .25 & 0.9 & $0.9-1.01$ & .13 \\
\hline Sex & 1.4 & $0.5-3.6$ & .48 & & & \\
\hline Initial NIHSS ( $\leq 20$ vs $>20$ ) & 0.8 & $0.3-2.1$ & .66 & & & \\
\hline ASPECTS ( $\leq 7$ vs $>7$ ) & 0.9 & $0.4-2.4$ & .89 & & & \\
\hline Dissection & 1.2 & $0.3-4.7$ & .77 & & & \\
\hline ICA occlusion & 1.8 & $0.7-4.7$ & .22 & & & \\
\hline IV tPA & 0.8 & $0.3-2.1$ & .69 & & & \\
\hline Onset-to-groin puncture & & & .58 & & & \\
\hline $270 \mathrm{~min}$ to $6 \mathrm{hr}$ vs $>360 \mathrm{~min}$ & 1.7 & $0.6-5.0$ & & & & \\
\hline$\leq 270 \min$ vs $>360 \mathrm{~min}$ & 1.7 & $0.5-5.7$ & & & & \\
\hline SVS+ & 5 & $1.6-16.6$ & $.01^{\mathrm{a}}$ & 8.7 & $1.1-69.4$ & $.04^{\mathrm{a}}$ \\
\hline $\begin{array}{l}\text { Lack of spontaneous } \\
\text { hyperattenuation on CT }\end{array}$ & 3.6 & $1.3-9.7$ & $.01^{\mathrm{a}}$ & 3.6 & $0.7-18.9$ & 013 \\
\hline Day 1 NIHSS ( $\leq 10$ vs $>10)$ & 51.5 & $11.8-225.1$ & $<.001^{\mathrm{a}}$ & 51.9 & $8.4-320.5$ & $<.001^{\mathrm{a}}$ \\
\hline $\mathrm{TICl}(\geq 2 \mathrm{~b}$ vs $<2 \mathrm{~b})$ & 5.1 & $1.4-17.9$ & $.01^{\mathrm{a}}$ & 7.1 & $0.4-112.8$ & .16 \\
\hline
\end{tabular}

${ }^{a}$ Significant.
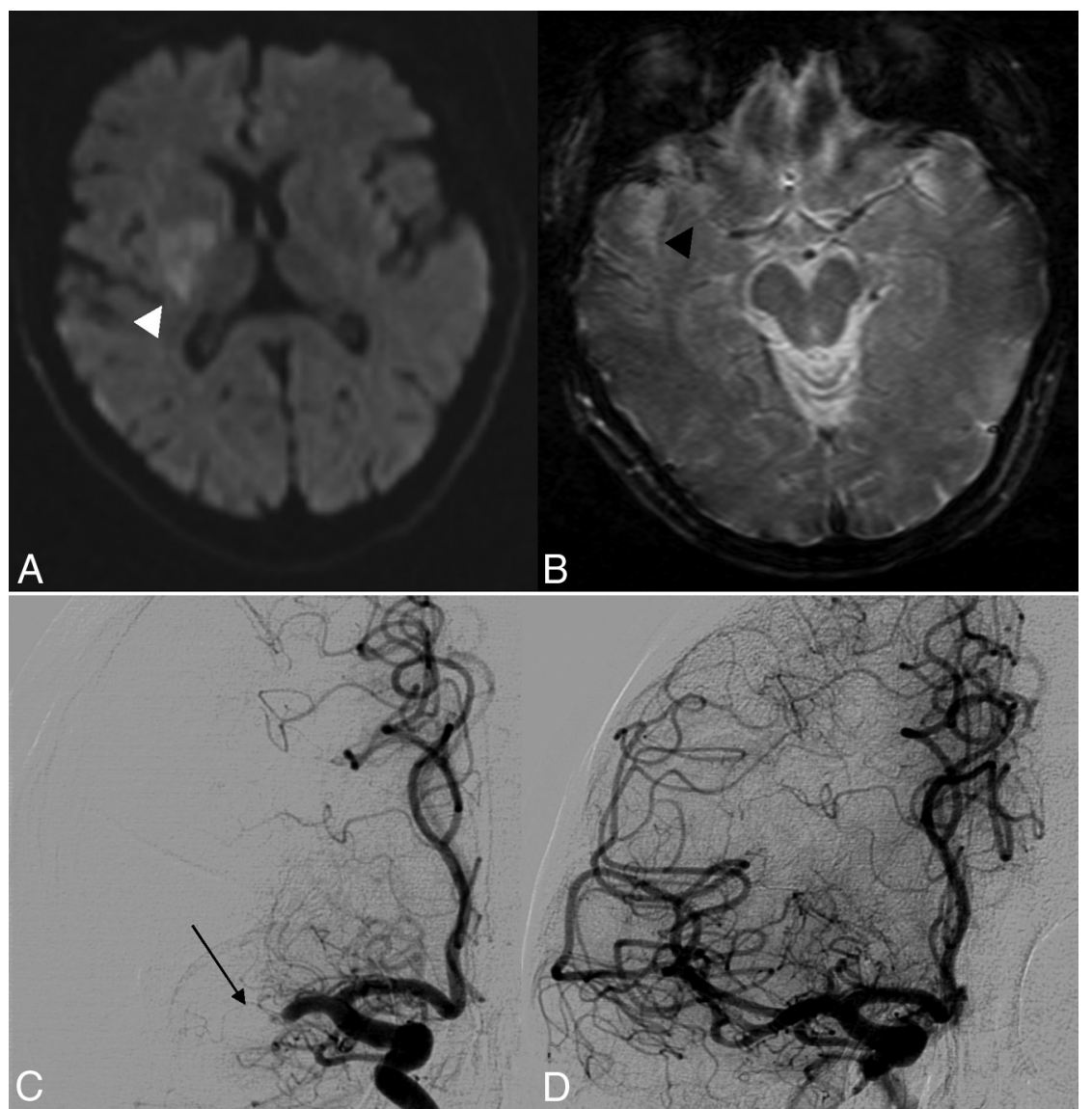

FIG 3. A 52-year-old patient with an initial NIHSS score of 19. At day 1 , the NIHSS score was 17 without recovery on the following days. There was no spontaneous hyperattenuation on CT at day 1. At 3 months, mRS was 4. A, DWI shows restriction of diffusion with an initial ASPECTS of 7 (white arrowhead). B, GRE T2* shows a right SVS- occlusion (black arrowhead). C, Pretreatment DSA shows right MCA occlusion (thin black arrow); the time between onset and groin puncture was 270 minutes. D, Post-MT DSA shows successful recanalization $(\mathrm{TICl} 3)$.

ports. ${ }^{13,14}$ The SVS + is related to the presence of either deoxyhemoglobin, intracellular methemoglobin, or hemosiderin in the red blood cell count of the clot. ${ }^{15,16}$ Moreover, red blood cell-rich clots originate from the cardiac system, whereas white thrombi (fibrin-rich) develop on ruptured atherosclerotic plaques. ${ }^{16}$
Kimura et $\mathrm{al}^{15}$ suggested that thrombi that integrate less deoxyhemoglobin, intracellular methemoglobin, or hemosiderin are SVS - and therefore younger. Our hypothesis is that younger thrombi (SVS-) are immediately symptomatic when developed in situ in cerebral atherosclerotic vessels. However, lack of histologic examination in our series does not allow any correlation between imaging findings and thrombus characteristics.

The SVS sign has been studied in the literature on ischemic stroke treated by IV tPA, with an end point defined either on TICI recanalization or mRS. Kimura et $\mathrm{al}^{15,17}$ focused on the potential of SVS to predict the success of IV tPA in 132 patients with MCA and ICA occlusions. In this retrospective study, they found that the SVS sign was the only independent factor predictive of early recanalization failure after IV tPA. No data were reported regarding the potential of SVS to predict mRS in this study. Similarly, Aoki et $\mathrm{al}^{14}$ found, in a retrospective study of 158 patients, that SVS+ was a predictor of both recanalization failure and worse mRS at 3 months and that patients with SVS- are better candidates for IV tPA. Regarding endovascular treatment, only 1 study investigated the impact of SVS in patients treated by MT, but it was limited to patients with SVS- ${ }^{13}$ In this study, the authors suggested that patients with SVS- could benefit from MT. However, it was performed on a small population of 11 patients, in which a combination of MT and intra-arterial thrombolysis was used in only 6 of the 11 patients. Our study compared the potential of SVS- and SVS+ to predict recanalization and mRS after MT, combining the use of a stent retriever with simultaneous continuous aspiration from the guiding catheter. We found a trend toward a better rate of recanalization in case of SVS+ compared with SVS $-(P=.34)$ and better clinical outcome $(P=.004)$, suggesting that as opposed to IV tPA studies, patients with SVS+ are better candidates for MT.

In the emergency context of an ACAS, one needs simple and reproducible biomarkers to decide whether to treat and whether to select either IV tPA or endovascular therapy. The Totaled Health Risks in Vascular Events score, MR imaging-DRAGON score, and ASPECTS help to decide whether to treat with IV tPA on the basis of a prognostic 


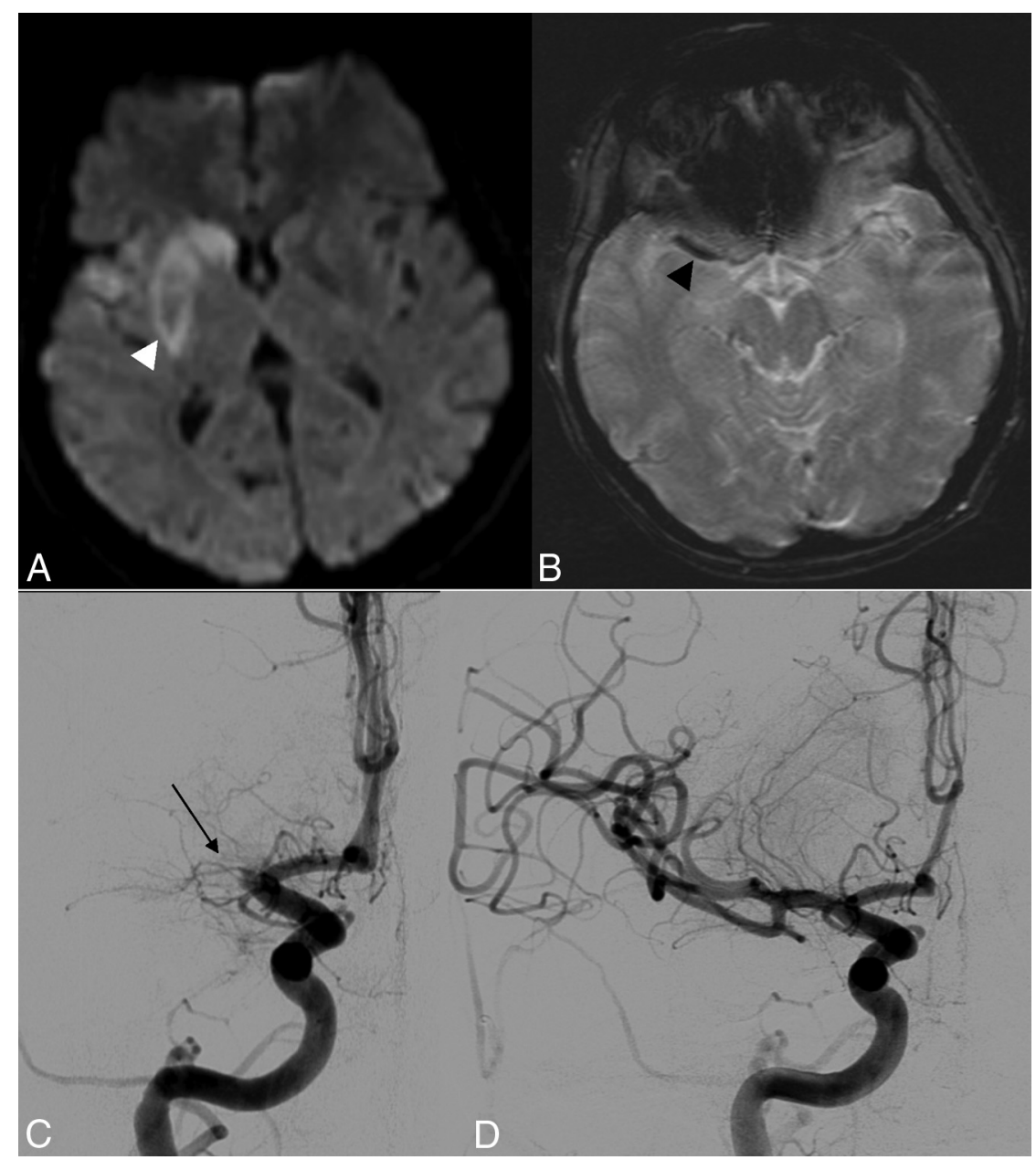

FIG 4. A 48-year-old patient with an initial NIHSS score of 21 and a 3-month mRS of 1 . A, DWI shows restriction of diffusion with an initial ASPECTS of 6 (white arrowhead). B, GRE T2* shows a right SVS+ occlusion (black arrowhead). C, Pretreatment DSA shows a right MCA occlusion (thin black arrow); the time between onset and groin puncture was 240 minutes. D, Post-MT DSA shows successful recanalization ( $\mathrm{TICl} 3$ ).

algorithm. ${ }^{18-21}$ The Diffusion and Perfusion Imaging Evaluation for Understanding Stroke Evolution Study 2 study helps select patients who can benefit from additional endovascular therapy on the basis of diffusion-perfusion mismatch. ${ }^{22}$ However, the interpretation of perfusion images is not easily reproducible among centers. ${ }^{23}$ Our study demonstrates that a simple and reproducible sign (SVS) on pretreatment MR imaging may help to select patients for MT and could be integrated in future prospective comparative trials.

It may be argued that GRE T2* and MR imaging are timeconsuming compared with CT. In the Multicenter Randomized Clinical Trial of Endovascular Treatment for Acute Ischemic Stroke in the Netherlands (MR CLEAN) and the Endovascular Treatment for Small Core and Proximal Occlusion Ischemic Stroke (ESCAPE) trial, ${ }^{3,4}$ patients were randomized on the basis of CT. As in other centers, we believe that MR imaging before treatment is, when available, the best imaging technique. ${ }^{24-26}$ Although we did not specifically measure the length of each MR imaging in our study, our MR imaging protocol is performed without injection and includes 4 short sequences, with an 11-minute acquisition time. This acquisition time is no longer than a CT scan, with and without contrast agent injection. Our results showing a potential predictive role of SVS support our strategy to recommend the use of MR imaging if available rather than CT in stroke evaluation.

Several limitations might apply to our study. IV tPA performed before MT, age, time between onset and groin puncture, initial stroke severity, stroke territory and subtype, imaging findings, and medical comorbidities might have influenced our recanalization and outcome results. ${ }^{27-29}$ However, these were similar between the 2 groups; this similarity made MT the major contributor to the TICI score and underlined the clinical outcome differences between the 2 groups. Even though better mRS scores were observed in the SVS + group $(P=$ .004), TICI scores did not present statistically significant differences between the 2 groups $(P=.34)$. This might be related to our small sample size and because patients with SVS- who presented initially with a good post-MT TICI score had delayed rethrombosis. Pre-existent underlying vessel disease, with atherosclerotic plaque or injured intima after numerous thrombectomy attempts, increases the risk of rethrombosis. ${ }^{30,31}$ However, because we did not perform a control DSA, we cannot demonstrate the validity of this hypothesis. Moreover, regarding the primary objective of our study, mRS was the most important parameter because it represented the clinical outcome (Figs 3 and 4). The presence of 11 cervical ICA dissections in our cohort might bias the recanalization rate and clinical outcome. ${ }^{32}$ In these patients, no significant difference between the SVS + and SVS - groups was found. Last, a good collateral circulation has been associated with better recanalization, reperfusion, and subsequent better clinical outcomes. ${ }^{33}$ We did not assess these collaterals in our study because we only performed a DSA in the concerned occluded vessel and not in the contralateral carotid artery. Although we performed a FLAIR sequence in all patients, it was not possible to assess collaterals because the FLAIR sequence has been well-validated for MCA occlusion only and not for ICA occlusion. ${ }^{34-36}$

\section{CONCLUSIONS}

Decision-making regarding patient eligibility for endovascular treatment is complex. There is a need for better selection of patients who might benefit most from endovascular stroke treatment. Our study focused on patients with ACAS treated with MT and showed that in this population, the presence of an SVS on MR imaging is a reliable, reproducible, and simple radiologic bio- 
marker that may predict favorable clinical outcome at 3 months after MT. Future prospective studies by using MR imaging and assessing the efficacy of endovascular treatment in ACAS should integrate SVS in their design.

\section{REFERENCES}

1. Nichols-Larsen DS, Clark PC, Zeringue A, et al. Factors influencing stroke survivors' quality of life during subacute recovery. Stroke 2005;36:1480-84 CrossRef Medline

2. Langhorne P, Coupar F, Pollock A. Motor recovery after stroke: a systematic review. Lancet Neurol 2009;8:741-54 CrossRef Medline

3. Berkhemer OA, Fransen PS, Beumer D, et al. A randomized trial of intraarterial treatment for acute ischemic stroke. NEngl J Med 2015; 372:11-20 CrossRef Medline

4. Goyal M, Demchuk AM, Menon BK, et al; ESCAPE Trial Investigators. Randomized assessment of rapid endovascular treatment of ischemic stroke. N Engl J Med 2015;372:1019-30 CrossRef Medline

5. Rovira A, Orellana P, Alvarez-Sabín J, et al. Hyperacute ischemic stroke: middle cerebral artery susceptibility sign at echo-planar gradient-echo MR imaging. Radiology 2004;232:466-73 CrossRef Medline

6. Flacke S, Urbach H, Keller E, et al. Middle cerebral artery (MCA) susceptibility sign at susceptibility-based perfusion MR imaging: clinical importance and comparison with hyperdense MCA sign at CT. Radiology 2000;215:476-82 CrossRef Medline

7. Barber PA, Hill MD, Eliasziw M, et al; ASPECTS Study Group. Imaging of the brain in acute ischaemic stroke: comparison of computed tomography and magnetic resonance diffusionweighted imaging. J Neurol Neurosurg Psychiatry 2005;76: 1528-33 CrossRef Medline

8. Costalat V, Machi P, Lobotesis K, et al. Rescue, combined, and standalone thrombectomy in the management of large vessel occlusion stroke using the Solitaire device: a prospective 50-patient singlecenter study: timing, safety, and efficacy. Stroke 2011;42:1929-35 CrossRef Medline

9. Tomsick T. TIMI, TIBI, TICI: I came, I saw, I got confused. AJNR Am J Neuroradiol 2007;28:382-84 Medline

10. Hacke W, Kaste M, Fieschi C, et al. Randomised double-blind placebo-controlled trial of thrombolytic therapy with intravenous alteplase in acute ischaemic stroke (ECASS II): Second EuropeanAustralasian Acute Stroke Study Investigators. Lancet 1998;352: 1245-51 CrossRef Medline

11. Hodel J, Leclerc X, Khaled W, et al. Comparison of 3D multi-echo gradient-echo and $2 \mathrm{D} \mathrm{T} 2{ }^{\star}$ MR sequences for the detection of arterial thrombus in patients with acute stroke. Eur Radiol 2014;24: 762-69 CrossRef Medline

12. Naggara O, Raymond J, Domingo Ayllon M, et al. T2* "susceptibility vessel sign" demonstrates clot location and length in acute ischemic stroke. PLoS One 2013;8:e76727 CrossRef Medline

13. Bae YJ, Jung C, Kim JH, et al. Potential for the use of the Solitaire stent for recanalization of middle cerebral artery occlusion without a susceptibility vessel sign. AJNR Am J Neuroradiol 2014;35:149-55 CrossRef Medline

14. Aoki J, Kimura K, Shibazaki K, et al. Location of the susceptibility vessel sign on $\mathrm{T} 2{ }^{*}$-weighted MRI and early recanalization within 1 hour after tissue plasminogen activator administration. Cerebrovasc Dis Extra 2013;3:111-20 CrossRef Medline

15. Kimura K, Sakamoto Y, Aoki J, et al. Clinical and MRI predictors of no early recanalization within 1 hour after tissue-type plasminogen activator administration. Stroke 2011;42:3150-55 CrossRef Medline

16. Cho KH, Kim JS, Kwon SU, et al. Significance of susceptibility vessel sign on $\mathrm{T} 2^{*}$-weighted gradient echo imaging for identification of stroke subtypes. Stroke 2005;36:2379-83 CrossRef Medline
17. Kimura K, Sakamoto Y, Iguchi $Y$, et al. Clinical and MRI scale to predict very poor outcome in tissue plasminogen activator patients. Eur Neurol 2011;65:291-95 CrossRef Medline

18. Flint AC, Cullen SP, Rao VA, et al; SWIFT and STAR trialists. The THRIVE score strongly predicts outcomes in patients treated with the Solitaire device in the SWIFT and STAR trials. Int J Stroke 2014; 9:698-704 CrossRef Medline

19. del Zoppo GJ, Higashida RT, Furlan AJ, et al; PROACT Investigators. PROACT: a phase II randomized trial of recombinant pro-urokinase by direct arterial delivery in acute middle cerebral artery stroke. Stroke 1998;29:4-11 CrossRef Medline

20. Turc G, Apoil M, Naggara O, et al. Magnetic resonance imagingDRAGON score: 3-month outcome prediction after intravenous thrombolysis for anterior circulation stroke. Stroke 2013;44: 1323-28 CrossRef Medline

21. Turc G, Aguettaz P, Ponchelle-Dequatre N, et al. External validation of the MRI-DRAGON score: early prediction of stroke outcome after intravenous thrombolysis. PLoS One 2014;9:e99164 CrossRef Medline

22. Inoue M, Mlynash M, Straka M, et al; DEFUSE 1 and 2 Investigators. Clinical outcomes strongly associated with the degree of reperfusion achieved in target mismatch patients: pooled data from the Diffusion and Perfusion Imaging Evaluation for Understanding Stroke Evolution studies. Stroke 2013;44:1885-90 CrossRef Medline

23. Dani KA, Thomas RG, Chappell FM, et al. Systematic review of perfusion imaging with computed tomography and magnetic resonance in acute ischemic stroke: heterogeneity of acquisition and postprocessing parameters-a translational medicine research collaboration multicentre acute stroke imaging study. Stroke 2012;43: 563-66 CrossRef Medline

24. Adams H, Adams R, Del Zoppo G, et al; Stroke Council of the American Heart Association; American Stroke Association. Guidelines for the early management of patients with ischemic stroke: 2005 guidelines update a scientific statement from the Stroke Council of the American Heart Association/American Stroke Association. Stroke 2005;36:916-23 CrossRef Medline

25. Chalela JA, Kidwell CS, Nentwich LM, et al. Magnetic resonance imaging and computed tomography in emergency assessment of patients with suspected acute stroke: a prospective comparison. Lancet 2007;369:293-98 CrossRef Medline

26. Wisco D, Uchino K, Saqqur M, et al. Addition of hyperacute MRI AIDS in patient selection, decreasing the use of endovascular stroke therapy. Stroke 2014;45:467-72 CrossRef Medline

27. Khatri P, Yeatts SD, Mazighi M, et al; IMS III Trialists. Time to angiographic reperfusion and clinical outcome after acute ischaemic stroke: an analysis of data from the Interventional Management of Stroke (IMS III) phase 3 trial. Lancet Neurol 2014;13:567-74 CrossRef Medline

28. Natarajan SK, Karmon Y, Snyder KV, et al. Prospective acute ischemic stroke outcomes after endovascular therapy: a realworld experience. World Neurosurg 2010;74:455-64 CrossRef Medline

29. Baker WL, Colby JA, Tongbram V, et al. Neurothrombectomy devices for the treatment of acute ischemic stroke: state of the evidence. Ann Intern Med 2011;154:243-52 CrossRef Medline

30. Marder VJ, Chute DJ, Starkman S, et al. Analysis of thrombi retrieved from cerebral arteries of patients with acute ischemic stroke. Stroke 2006;37:2086-93 CrossRef Medline

31. Kalinowski M, Wagner HJ. Adjunctive techniques in percutaneous mechanical thrombectomy. Tech Vasc Interv Radiol 2003;6:6-13 CrossRef Medline

32. Machi P, Lobotesis K, Maldonado IL, et al. Endovascular treatment of tandem occlusions of the anterior cerebral circulation with Solitaire FR thrombectomy system: initial experience. Eur J Radiol 2012;81:3479-84 CrossRef Medline 
33. Bang OY, Saver JL, Kim SJ, et al. Collateral flow predicts response to endovascular therapy for acute ischemic stroke. Stroke 2011;42: 693-99 CrossRef Medline

34. Liu W, Xu G, Yue X, et al. Hyperintense vessels on FLAIR: a useful non-invasive method for assessing intracerebral collaterals. Eur $J$ Radiol 2011;80:786-91 CrossRef Medline

35. Azizyan A, Sanossian N, Mogensen MA, et al. Fluid-attenuated in- version recovery vascular hyperintensities: an important imaging marker for cerebrovascular disease. AJNR Am J Neuroradiol 2011; 32:1771-75 CrossRef Medline

36. Sanossian N, Saver JL, Alger JR, et al. Angiography reveals that fluidattenuated inversion recovery vascular hyperintensities are due to slow flow, not thrombus. AJNR Am J Neuroradiol 2009;30:564-68 CrossRef Medline 